\title{
Consumer Acceptability of Aquaponically Grown Basil
}

\author{
Chengyan Yue
}

Department of Applied Economics and Department of Horticultural Science, University of Minnesota, 458 Alderman Hall, 1970 Folwell Avenue, St. Paul, MN 55108

\section{Zata Vickers}

Sensory Center, Department of Food Science and Nutrition, University of Minnesota, 1334 Eckles Avenue, St. Paul, MN 55108

\author{
Jingjing Wang \\ College of Economics and Management, China Agricultural University, \\ Beijing 100083, China
}

Neil O. Anderson

Department of Horticultural Science, University of Minnesota, 286 Alderman Hall, 1970 Folwell Avenue, St. Paul, MN 55108

\author{
Lauren Wisdorf and Jenna Brady \\ Sensory Center, Department of Food Science and Nutrition, University of \\ Minnesota, 1334 Eckles Avenue, St. Paul, MN 55108
}

Michele Schermann

Department of Horticultural Science, University of Minnesota, 286 Alderman Hall, 1970 Folwell Avenue, St. Paul, MN 55108

\section{Nicholas Phelps}

Department of Fisheries, Wildlife and Conservation Biology, University of Minnesota, 135 Skok Hall, 2003 Upper Buford Circle, Suite 135, St. Paul, MN 55108

\section{Paul Venturelli \\ Department of Biology, Ball State University, 121 Cooper Life Science Building, 2111 W. Riverside Avenue, Muncie, IN 47306}

Additional index words. Cyprinus carpio (koi), deep water culture, ebb and flow, greenhouse, warehouse

\begin{abstract}
The present study systematically investigated the effects of warehouse and greenhouse aquaponic growing conditions on consumer acceptability of different basil cultivars. A total of 105 consumers rated their liking of three basil cultivars (Nufar, Genovese, and Eleonora), each grown in three conditions (aquaponically in a greenhouse, aquaponically in a warehouse, both with Cyprinus carpio, Koi fish, and grown in soilless medium). We used linear random effect models to investigate consumer preferences for attributes of basil plants grown in different environments by controlling for individualspecific random effects. Participants generally liked the soilless medium-grown and greenhouse aquaponically grown basil plants more than the warehouse aquaponically grown plants. The soilless medium-grown basil had the highest appearance liking and flavor intensity, followed by the greenhouse aquaponic grown and then by the warehouse aquaponic grown. Aquaponically grown cultivars were rated less bitter than soilless medium-grown cultivars.
\end{abstract}

Aquaponics, also known as the integration of aquaculture and hydroponics (Love et al., 2015), has attracted growing interest from producers and researchers around the globe. With the combination of the hydroponic production of plants and the aquaculture production of fish, aquaponics is a sustainable agricultural system in which nutrient-supplemented water, generated from fish production, serves as a liquid fertilizer to hydroponically grown plants (Love et al., 2015; Savvas and Gruda, 2018). After a biofilter treatment, the hydroponic plants use the nitrate-nitrogen from the fish waste, so that both water resources and plant nutrition can be conserved (Diver and Rinehart, 2000; Somerville et al., 2014; Tyson et al., 2011). Aquaponics has the potential to increase agricultural production by growing plants year-round in a controlled, soilless medium environment (Coyle and Ellison, 2017; Savidov, 2004; Short et al., 2018). With aquaponics systems, crops like lettuce and herbs can be produced in nontraditional areas, and consumers in urban areas can get locally produced crops (Coyle and Ellison, 2017).

Ocimum basilicum L. (basil), one of the most popular fresh culinary herbs, is a highvalue, short-season crop (Ferrarezi and Bailey, 2019). For centuries, fresh and dried basil leaves have been used as a common spice for cooking, the essential oils and aromatic extract are also widely used in oral and skin care in clinical settings by virtue of their health benefits (Singletary, 2018). A small number of studies have investigated the production performance and nutrition of aquaponically grown basil. Aquaponically grown basil showed good adaptation in warm tropical conditions, and the yield was higher than that obtained from other hydroponic crops (Ferrarezi and Bailey, 2019). Although some researchers have argued that aquaponic growing methods do not necessarily result in higher yields, they do keep water quality stable (Wilson, 2017). Walters and Currey (2015) compared production systems and cultivars for hydroponic greenhouse basil plants, and suggested that the yield of fresh basil was affected more by cultivar selection than by the hydroponic production system. Cultivars such as Genovese and Spicy Globe have been identified as the highest yielding cultivars in summer and fall in aquaponic systems (Ferrarezi and Bailey, 2019). 'Nufar', compared with other cultivars including Genovese, not only produced greater yields, but was more resistant to Fusarium oxysporum f. sp. basilici (fusarium wilt), a common fungal disease in basil production (Walters and Currey, 2015).

Studies on aquaponics production have emphasized the environmental and economic benefits of aquaponic growing systems compared with hydroponics (Tyson et al., 2011). Several researchers have investigated consumer perceptions and willingness to pay for aquaponically grown produce. Although aquaponic produce was considered an innovative and unfamiliar food category (Tamin et al., 2015), consumers viewed aquaponics as having positive impacts on the environment (Short et al., 2017), and many saw aquaponics as an acceptable form of alternative farming (Coyle and Ellison, 2017). Consumers' willingness to pay for aquaponically grown lettuce was similar to that of soillessproduced lettuce (Coyle and Ellison, 2017; Short et al., 2017). There is a potential niche market for sustainable, local, and green aquaponic products (Tamin et al., 2015). However, limited studies examined the consumer acceptability of the aquaponic produce based on consumers' evaluation of intrinsic attributes (for instance, visual appearance, color, flavor, taste). To better understand consumers' food selection behaviors for various cultivars in different growing systems, we need to compare consumer acceptability among aquaponically and soilless mediumgrown produce. 
The objective of this research was to measure and compare consumer acceptability of three cultivars of basil (Nufar, Genovese, and Eleonora) grown in three different conditions (soilless medium as a control; greenhouse aquaponics and warehouse aquaponics, both using Koi fish). This study contributes to the literature in several ways. First, we examined the acceptability of aquaponically grown basil leaves when participants in the experiment were not given any growing information. The acceptabilities were measured and compared, based on consumer preferences for the intrinsic attributes. Second, existing research on consumer acceptability of aquaponic products has largely focused on consumer perceptions of the aquaponics production method but ignored the factors affecting the real-time experience of consumers. The present study with sensory evaluation fills this gap. Third, a linear mixed effect model was used to control for consumers' individual random effects when evaluating the differences in acceptability of different basil products. To the best of our knowledge, this is the first study on consumer taste sensitivity and the acceptability of aquaponically grown basil cultivars. This research will help determine which sensory attributes are most valued by basil consumers.

\section{Materials and Methods}

The data provided for this study come from a sensory test focusing on consumer acceptability of different basil cultivars grown in three different growing conditions.

Basil products. In May 2017, we harvested three basil cultivars (Nufar, Genovese, and Eleonora; seed lots obtained from Johnny's Seed Co., Winslow, ME), each grown in three environmental conditions (aquaponically in a greenhouse using koi fish, aquaponically in a warehouse using koi fish, and grown in soilless medium). The choice of basil cultivars was based on an informal poll of aquaponic and hydroponic growers in Minnesota. Cultivars chosen reflected the best ones to capture market share in the upper Midwest fresh herb market. The basil cultivars are all open-pollinated cultivars and inherently genetically different from each other (https://www.johnnyseeds.com/

Received for publication 14 Jan. 2020. Accepted for publication 5 Mar. 2020.

Published online 1 May 2020

This research was supported, in part, by a grant from the University of Minnesota Global Food Ventures MNDrive and the Minnesota Agricultural Experiment Station.

C.Y., Z.V., and N.O.A. are Professors.

J.W. and L.W. were Graduate Research Assistants at the University of Minnesota during the study.

J.B. and M.S. are Research Scientists.

N.P. and P.V. are Assistant Professors.

J.W. is the corresponding author. E-mail: wang2797@ umn.edu.

This is an open access article distributed under the CC BY-NC-ND license (https://creativecommons. org/licenses/by-nc-nd/4.0/). herbs/). 'Nufar' basil is a 77-d cultivar with sweet-scented, 10.16-cm (4-inch) leaves. It has partial Fusarium resistance. In contrast, Genovese Compact Improved is an earlier cultivar (74-d) of classic Italian flavor type. Its tall plants are slow to bolt (flower) and sport large, dark-green 7.62-cm (3-inch) leaves; the flowers are also edible. Elenora is the earliest one grown, a 65 -d cultivar, with characteristic 7.62-cm (3-inch) cupped leaves and a spicy flavor. This cultivar has partial downy mildew resistance. The basil leaves were harvested from greenhouses and a warehouse located in the MinneapolisSaint Paul Metropolitan area, State of Minnesota, specifically at the St. Paul Campus of the University of Minnesota (lat. 44 $59^{\prime} 17.8^{\prime \prime}$ $\mathrm{N}$, long. $\left.-93^{\circ} 10^{\prime} 51.6^{\prime \prime} \mathrm{W}\right)$.

Growing conditions. Exact growing conditions of the three treatments are identical to those delineated by Abbey et al. (2019a, 2019b). Briefly, for the soilless medium treatment, the greenhouse environmental conditions were $24.4 \pm 3.0 / 18.3 \pm 1.5{ }^{\circ} \mathrm{C}$ day/night daily integral and a 16-h-long day photoperiod (0600-2200 HR) lighting (400W high-pressure sodium high-intensity discharge lamps, HPS-HID) at a minimum of $150 \mu \mathrm{mol} \cdot \mathrm{m}^{-2} \cdot \mathrm{s}^{-1}$ (Abbey et al., 2019a). The soilless medium used was Sunshine LC8 soilless potting medium (Sun Gro Horticulture, Agawam, MA). We know of no effect elicited by growing basil in the soilless medium compared with aquaponic growing conditions, hence the objective of this study. All greenhouse aquaponic systems, regardless of the type of growing structures, had a $23.6+0.8{ }^{\circ} \mathrm{C}$ daily integral, based on a temperature setpoint of $23.5^{\circ} \mathrm{C}$. Lighting was supplied during winter months and cloudy days with a 16-h photoperiod (0600$2200 \mathrm{HR}$; long days) by (400-W HPS-HID) at a minimum of $150 \mu \mathrm{mol} \cdot \mathrm{m}^{-2} \cdot \mathrm{s}^{-1}$. Our warehouse aquaponic system was contained within a retrofitted walk-in cooler $(7.19 \times$ $4.87 \times 2.74 \mathrm{~m})$, in the basement of the Plant Growth Facilities headhouse, which had galvanized interior walls and an F5 Fantastically Fun Fresh Food Factory commercial-type closed aquaponic system installed from Nelson and Pade Company (http://aquaponics.com/; Montello, WI). An LED lighting system from Agrivolution LLC (http://www.agrivolution.co/; South Windsor, CT) had a triple-band LED light (bar) above the plants, which telescoped vertically, depending on the plant height. The LEDs have single-chip diodes emitting blue, green, and red light with full photosynthetically active radiation $(P A R=400 \mathrm{~nm}$ to $700 \mathrm{~nm})$. Supplemental cooling is supplied to maintain average growing temperatures of 20 to $21{ }^{\circ} \mathrm{C}$ day/night.

Treatments were identified as follows and supplied to each participant with a code number:

- 'Nufar' in soilless medium (control)

- 'Nufar' in greenhouse aquaponics

- 'Nufar' in warehouse aquaponics
- 'Genovese' in soilless medium (control)

- 'Genovese' in greenhouse aquaponics

- 'Genovese' in warehouse aquaponics

- 'Eleonora' in soilless medium (control)

- 'Eleonora' in greenhouse aquaponics

- 'Eleonora' in warehouse aquaponics

Samples were harvested the afternoon before the test day, washed, blotted dry with paper towels, and placed into coded (random 3-digit numbers) sandwich-sized zip-closed bags (up \& up; Target Corporation, Minneapolis, MN). These bags of basil were stored in a refrigerator overnight $\left(3\right.$ to $\left.5{ }^{\circ} \mathrm{C}\right)$, removed from the refrigerator the morning of the test, and were held at ambient temperature $\left(\approx 21^{\circ} \mathrm{C}\right)$ until serving (no longer than $4 \mathrm{~h}$ ). Each participant received one basil leaf per sample in an individually coded plastic bag. Participants were given a sample at a time in a random order to avoid the reference point effect. Participants were given a palate cleanser between the samples.

Participants. A total of 105 participants were recruited from students and staff of the University of Minnesota who expressed an interest in participating in sensory tests. The experiment was conducted at the University of Minnesota in May 2017. Eligible participants were 18 years or older and had no food allergies. Participants were paid $\$ 10$ after completing the test. The recruiting and experimental procedures were approved by the Institutional Review Board at the University of Minnesota.

Experimental procedure. Basil leaves served to participants were balanced for order and carryover effects using a Williams Latin square design (Wang et al., 2009). Participants were instructed to taste each leaf and rate overall liking, appearance liking, flavor liking, flavor intensity, bitterness intensity, and texture liking (Table 1). They made liking ratings on labeled affective magnitude (LAM) scales. With numeric labels illustrating the absolute ratings of liking/disliking, the LAM was easy to use and provided greater discrimination among similar foods (Schutz and Cardello, 2001). For all the ratings except for intensity, the LAM scales were 120-point line scales with the leftmost ends labeled greatest imaginable disliking (point value of 0), and the rightmost ends labeled greatest imaginable liking (point value of 120) (Table 1). Intensity (flavor intensity and bitterness intensity) ratings were made on 20-point line scales with the leftmost ends labeled none and the rightmost ends labeled intense (Table 1). The participants were presented with the product code for each treatment during the experiment, but they did not know the name of cultivars or production methods. After evaluating all nine basil samples, participants answered a series of demographic questions (Table 1).

Statistical analysis. We used a repeated and mixed measure of analyses of variance (ANOVAs) to determine whether the cultivars or growing conditions differed in any of the six variables: overall liking, flavor liking, texture liking, appearance liking, flavor intensity, and 
Table 1. Testing score sheets used by participants for the basil sensory evaluations. Ratings by cultivar for overall liking, flavor liking, texture liking, appearance liking, flavor intensity, and bitterness. Liking ratings were made on 120-point labeled affective magnitude scales, with the leftmost ends labeled greatest imaginable disliking and the rightmost ends labeled greatest imaginable liking. Intensity ratings were made on 20-point line scales with the leftmost ends labeled none and the rightmost ends labeled intense.

\section{Place a mark on the line below to indicate your overall liking of the sample}

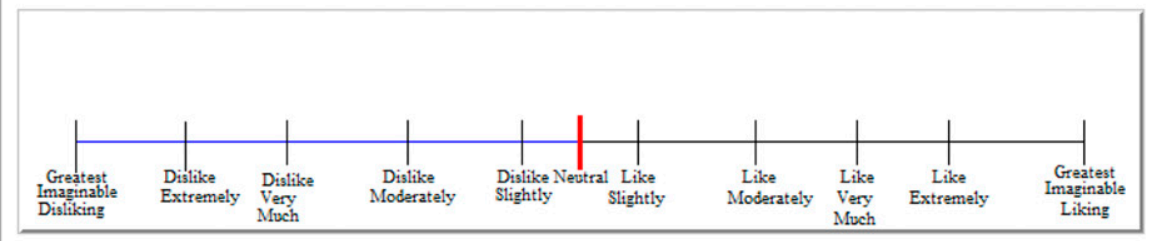

Place a mark on the line below to indicate your liking of the appearance

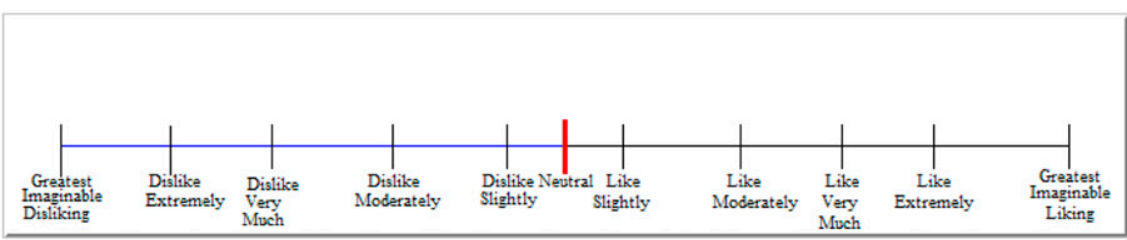

Place a mark on the line below to indicate your liking of the flavor

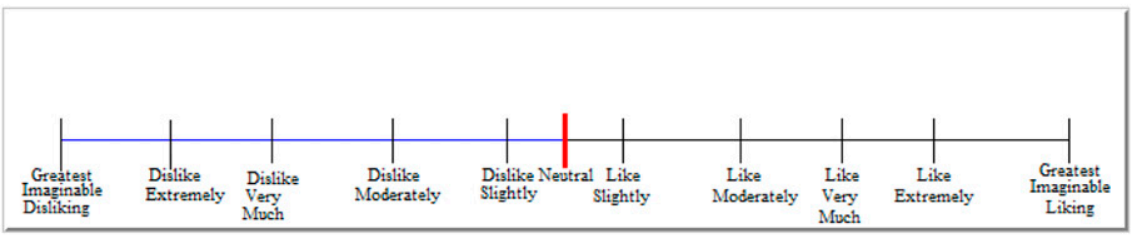

Rate the bitterness of the basil sample

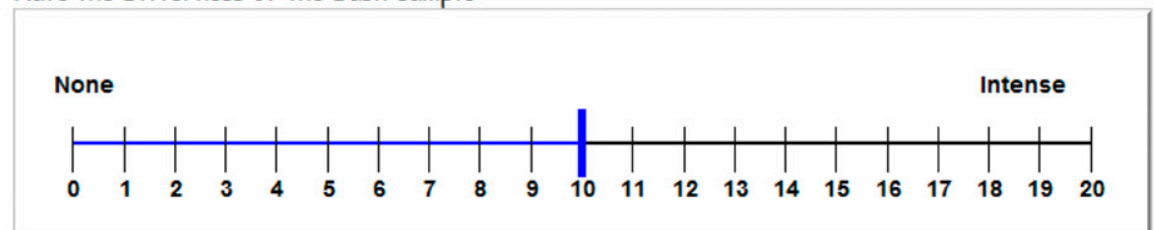

Place a mark on the line below to indicate your liking of the texture

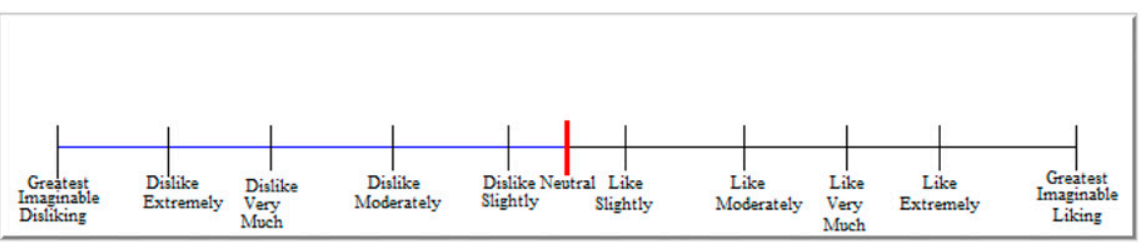

\footnotetext{
How often do you buy fresh vegetables?

$\square$ More than once a week

$\square$ Once a week

$\square$ Two or three times a month

$\square$ Once a month

$\square$ Only when in season

$\square$ Never or less than once a month
} 
What types of stores do you buy most of your fresh vegetables from?

$\square$ Mass merchandiser (e.g. Wal-Mart)

$\square$ Co-ops

$\square$ High end specialty stores (e.g. Lunds)

$\square$ Supermarket (e.g. Cub)

$\square$ Convenience stores (e.g. Holiday)

$\square$ Discount stores (e.g. Aldi, Trader Joes)

$\square$ Roadside stand or Farmer's market

Do you belong to any environmental groups?

$\square$ Yes

$\square$ No

What is the highest level of education you have completed?

$\square$ some high school or less

$\square$ high school diploma/GED

$\square$ some college

$\square$ associate's degree

$\square$ college diploma

$\square$ some graduate school

$\square$ graduate/professionals degree

What is your gender?

$\square$ Male

$\square$ Female

What is your marital status?

$\square$ not married/single

$\square$ in a relationship

$\square$ married

$\square$ divorced/separated

$\square$ wido/widower

Do you have children under 12 years old?

$\square$ yes

$\square$ no

How many people live in your household? Include yourself, spouse, and any dependents. Do not include roommates.

1 1

$\square 2$

$\square 3$

$\square 4$

$\square 5$

$\square 6$

$\square 7$

$\square 8$

$\square 9$

$\square 10$ or more

Please circle the category below that describes the total amount of INCOME earned last year by the people in your household. $\square \$ 15,000$ or under

$\square \$ 15,001-\$ 25,000$

$\square \$ 25,001-\$ 35,000$

$\square \$ 35,001-\$ 50,000$

$\square \$ 50,001-\$ 65,000$

$\square \$ 65.001-\$ 80,000$

$\square \$ 80,001-\$ 100,000$

$\square \$ 100,001-\$ 150,000$

$\square$ Over $\$ 150,000$

What is your current employment status?

$\square$ Full time

$\square$ Part time

$\square$ Student

$\square$ Retired

$\square$ Unemployed

$\square$ NA 
bitterness intensity. Variables such as cultivar, growing condition, and cultivar $\times$ growing condition were included as fixed predictors, and the individual participant was included as a random predictor in the models. We also used post hoc pairwise comparison (StudentNewman-Keuls tests) to determine whether differences among specific cultivars and specific growing conditions were significant $(\alpha=0.05)$.

To further analyze the relationship between consumer acceptability and different growing conditions for three basil cultivars, we used linear mixed effect models and controlled for both observable and unobservable interindividual variations in acceptability.

The model for respondent $i$ and attribute $t$ can be written as follows:

$$
\begin{aligned}
& y_{i t}=\alpha+\beta_{1} \text { GreenhouseAquaponics }_{t} \\
& +\beta_{2} \text { WarehouseAquaponics }_{t} \\
& +\beta_{3} \text { Genovese }_{t} \\
& +\beta_{4} \text { Eleonora }_{t} \\
& +\beta_{5} \text { (GreenhouseAquaponics } * \text { Genovese }{ }_{t} \\
& +\beta_{6}(\text { GreenhouseAquaponics } * \text { Eleonora })_{t} \\
& \left.+\beta_{7} \text { (WarehouseAquaponics } * \text { Genovese }\right)_{t} \\
& +\beta_{8}(\text { WarehouseAquaponics } * \text { Eleonora })_{t} \\
& +\gamma \boldsymbol{X}_{i}+v_{i}+\varepsilon_{i t}
\end{aligned}
$$

where $i$ represents a given respondent, and $t$ is a given attribute of the basil product. The dependent variables, $y_{i t}$, are the individualspecific ratings on different attributes $(t)$ of the basil products. The model included the product-specific variables, such as production methods, basil cultivars, and the interaction terms; the individual-specific variables, $\boldsymbol{X}_{\boldsymbol{i}}$, such as respondents' socioeconomic status; the unobserved random individual effect, $v_{i}$; and $\varepsilon_{i t}$ is the unobserved random error term. $\alpha$ is the constant term, $\beta$ and $\gamma$ are the vectors of corresponding parameters for product-specific and individual-specific variables. Two specifications with and without the production treatments and cultivar interactions were conducted. In all the specifications, the Nufar cultivar grown in the soilless medium was used as the base group for estimation. The mixed model ANOVA and the mixed effect model were analyzed using Stata 14 (StataCorp, College Station, TX). All statistical tests were carried out with $\alpha=0.05$.

\section{Results}

Consumers' sociodemographic information. Participants' ages ranged from 18 to 70 years, with the average $\approx 35$ (Table 2 ). With respondents from the university staff and students, more than half of our sample had some graduate school education, $\approx 33 \%$ had associate degrees or college diplomas, and $13 \%$ had high school or some college education. Approximately $21 \%$ of the respondents were male, and fewer than half were married. Only $15 \%$ of the respondents had a child younger than 12 in the household. The average household had two people, with a median household income ranging from $\$ 35,000$ to $\$ 50,000$. Forty-seven percent of the respondents bought vegetables at least once a week (Table 2). Compared with the Minnesota population, our sample was younger, more educated, and consisted of more females.

Differences among cultivars. Participants rated overall liking, flavor liking, texture liking, and flavor intensity of Nufar higher than the other cultivars (Table 3). However, ratings of bitterness did not differ significantly among the three cultivars (Table 3 ).

Differences among growing conditions. Participants liked (overall liking and texture liking) basil grown in the soilless medium and greenhouse aquaponics conditions more than the basil grown in the warehouse aquaponics condition (Table 4). They liked the appearance of the basil plants grown in the soilless medium more than those grown in the warehouse, with plants grown in the greenhouse falling in-between. Participants liked the flavor of the basil grown in the greenhouse aquaponics environment more than the basil grown in the other two environments. The soilless medium growing condition pro- duced basil with the highest flavor intensity, followed by the greenhouse aquaponics and then by the warehouse aquaponics. The soilless medium growing condition produced more bitter basil than the other growing conditions. (Table 4).

Estimation results from the linear mixed effects model regressions. The estimation results for the linear mixed effects model are presented in Table 5. The individual random effects have significant standard deviations, and the variances for the residuals are also significant, suggesting that the perceptions of the basil cultivars' performance are individual-specific. With individual random effects and sociodemographic backgrounds controlled, Genovese and Eleonora cultivars were rated significantly lower, compared with Nufar, on almost all sensory attributes except for bitterness. No significant differences were identified among three cultivars for bitterness. When the fixed effects of different cultivars were controlled, cultivars grown in warehouse aquaponics were rated significantly lower than soilless-grown cultivars on overall liking, appearance liking, flavor intensity, bitterness, and texture liking. Basil cultivars grown in greenhouse aquaponics were rated lower on appearance, flavor intensity, and bitterness, compared with soilless medium-grown cultivars. The negative coefficients of warehouse aquaponics were much larger in magnitude than the coefficients of greenhouse aquaponics for flavor intensity, liking of appearance, and texture, demonstrating that warehouse aquaponics was the least preferred in terms of these three attributes. Greenhouse aquaponics got the lowest ratings on bitterness. Compared with soilless medium-grown breed, greenhouse aquaponics breed was preferred in terms of flavor liking, but warehouse aquaponics was not.

In addition, some of the individual demographics had significant impacts on respondents' sensory ratings. For instance, more

Table 2. Summary statistics of the demographic background of participants $(\mathrm{N}=105)$ in the basil sensory evaluation experiment.

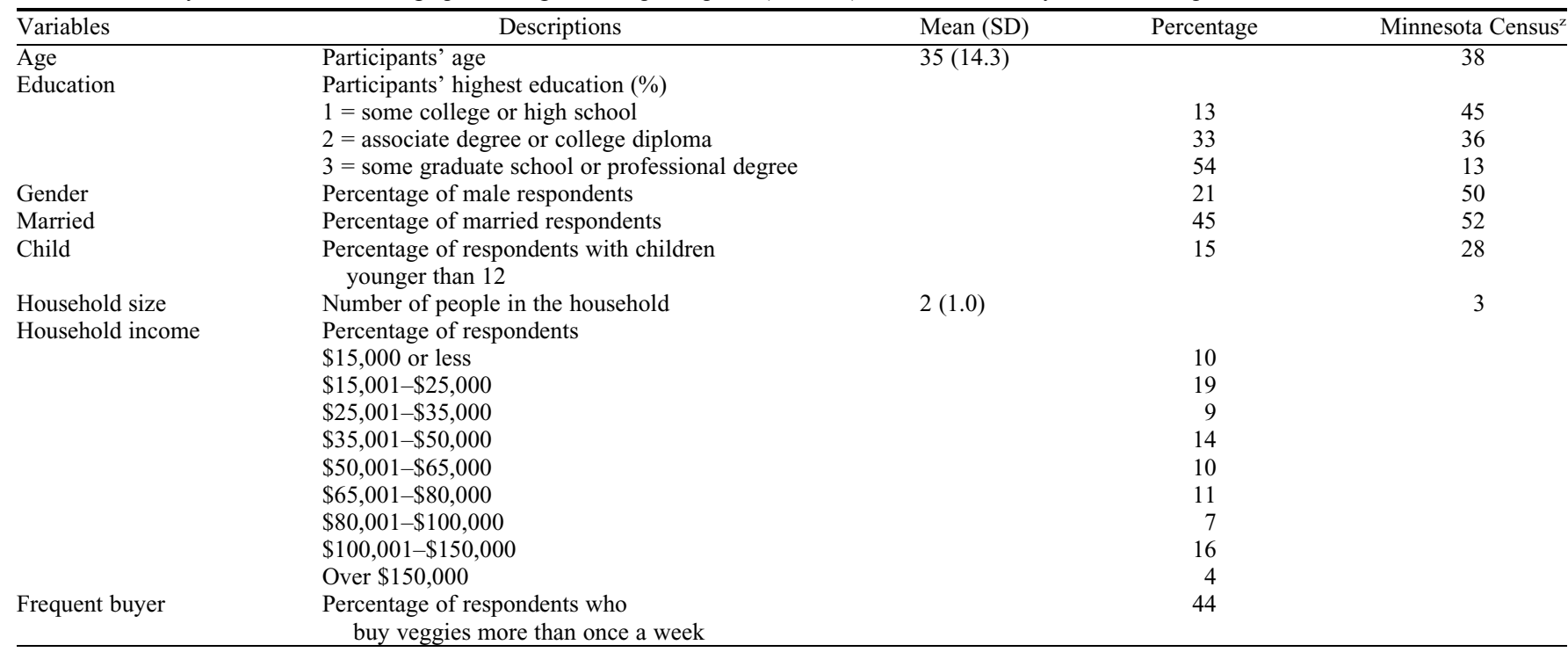

\footnotetext{
${ }^{\mathrm{z}}$ Source: U.S. Census Bureau, 2017 American Community Survey 1-Year Estimates.
} 
Table 3. Mean $(\mathrm{N}=105)$ ratings by cultivar for overall liking, flavor liking, texture liking, appearance liking, flavor intensity, and bitterness. ${ }^{2}$

\begin{tabular}{lccrrr}
\hline & \multicolumn{3}{c}{ Cultivar } & Stats \\
\cline { 2 - 5 } Attribute & Nufar & Genovese & Eleonora & F-value & 8.84 \\
\hline Overall liking & $69 \mathrm{a}^{\mathrm{y}}$ & $63 \mathrm{~b}$ & $65 \mathrm{~b}$ & $<0.001$ \\
Appearance liking & $77 \mathrm{a}$ & $66 \mathrm{c}$ & $72 \mathrm{~b}$ & $<0.001$ \\
Flavor liking & $66 \mathrm{a}$ & $60 \mathrm{~b}$ & $62 \mathrm{~b}$ & 6.22 & 0.002 \\
Flavor intensity & $11 \mathrm{a}$ & $10 \mathrm{~b}$ & $10 \mathrm{~b}$ & $<.28$ & 1.3 \\
Bitterness & 7 & 7 & 7 & $<0.001$ \\
Texture liking & $76 \mathrm{a}$ & $70 \mathrm{~b}$ & $72 \mathrm{~b}$ & 0.284 \\
\hline
\end{tabular}

${ }^{\mathrm{z}}$ Liking ratings were made on 120-point labeled affective magnitude scales, with the leftmost end labeled greatest imaginable disliking and the rightmost end labeled greatest imaginable liking. Intensity ratings were made on 20-point line scales with the leftmost ends labeled none and the rightmost ends labeled intense.

${ }^{\mathrm{y}}$ Mean ratings within a row having lowercase letters in common do not differ significantly (Student-Newman-Keuls test, $P>0.05$ ).

Table 4. Mean ratings by growing condition for overall liking, flavor liking, texture liking, appearance liking, flavor intensity, and bitterness. ${ }^{\mathrm{z}}$

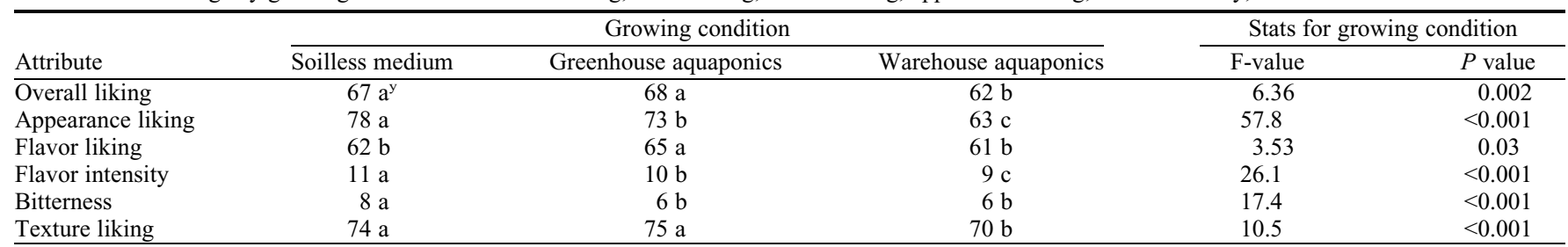

${ }^{\mathrm{z}}$ Liking ratings were made on 120-point labeled affective magnitude scales, with the leftmost end labeled greatest imaginable disliking and the rightmost end labeled greatest imaginable liking ( $c f$. Table 1). Intensity ratings were made on 20-point line scales with the leftmost ends labeled none and the rightmost ends labeled intense ( $c f$. Table 1).

${ }^{\mathrm{y}}$ Mean ratings within a row having lowercase letters in common do not differ significantly (Student-Newman-Keuls test, $P>0.05$ ).

Table 5. Estimation results from linear mixed effects model assessing effects of different basil cultivars and treatments on sensory ratings for overall liking, flavor liking, texture liking, appearance liking, flavor intensity, and bitterness. ${ }^{\mathrm{z}}$

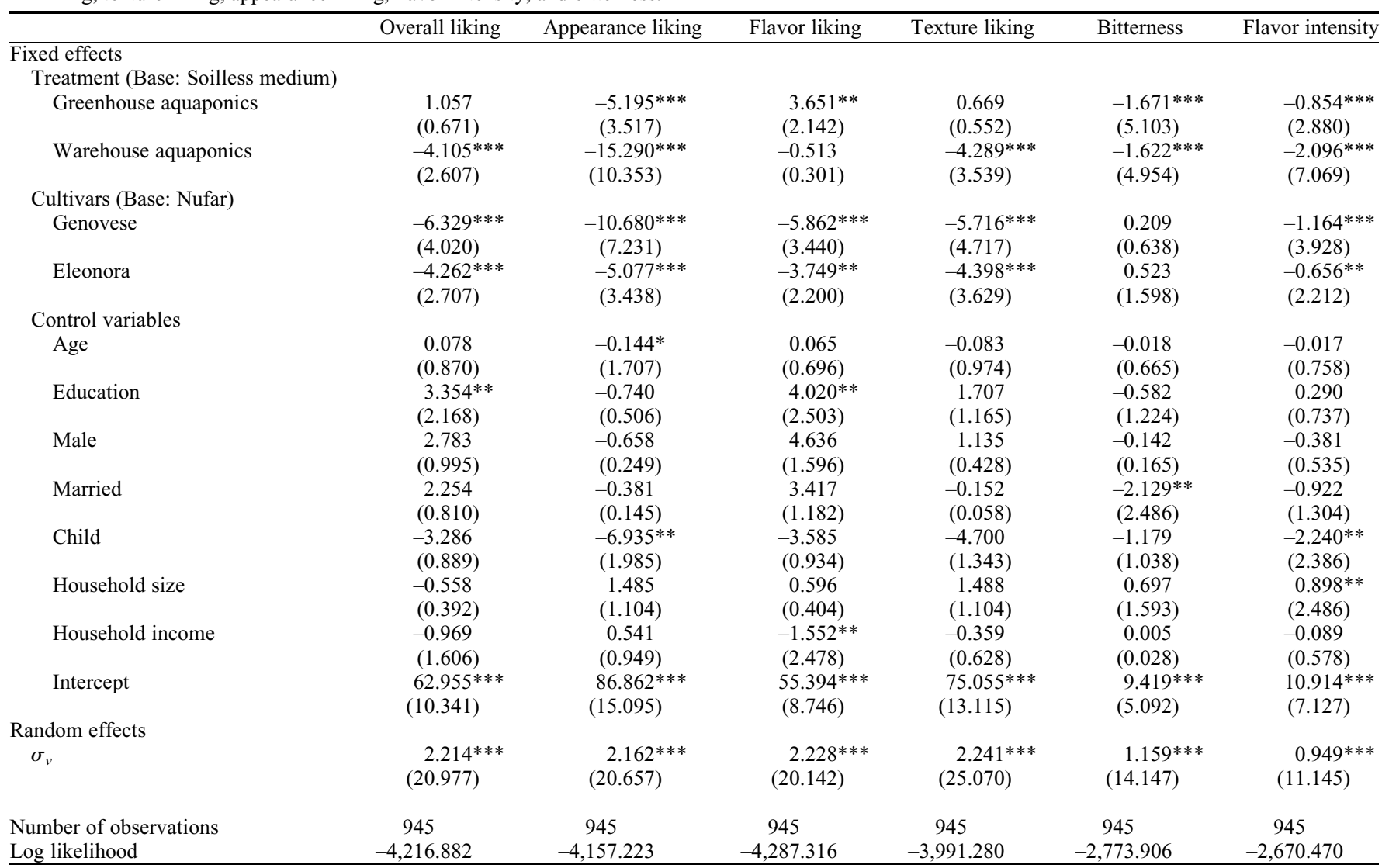

${ }^{\mathrm{z}}$ The base group cultivar is soilless medium-grown 'Nufar'. Absolute t statistics in parentheses. ${ }^{*} P<0.1, * * P<0.05$, *** $P<0.01$.

educated respondents tended to have higher ratings for overall liking and flavor liking. Compared with respondents with no children, the presence of children lowered the ratings on most of the sensory attributes. Respondents with children had lower ratings on appearance liking and flavor intensity. Married respondents had lower ratings of bitterness.
Interactions between cultivars and growing conditions. The regression results for the linear mixed effect model with interactions between cultivars and growing 
Table 6. Estimation results from linear mixed effects model assessing effects of different basil cultivars, treatments, and cultivar $\times$ treatment interactions on sensory ratings for overall liking, flavor liking, texture liking, appearance liking, flavor intensity, and bitterness. ${ }^{2}$

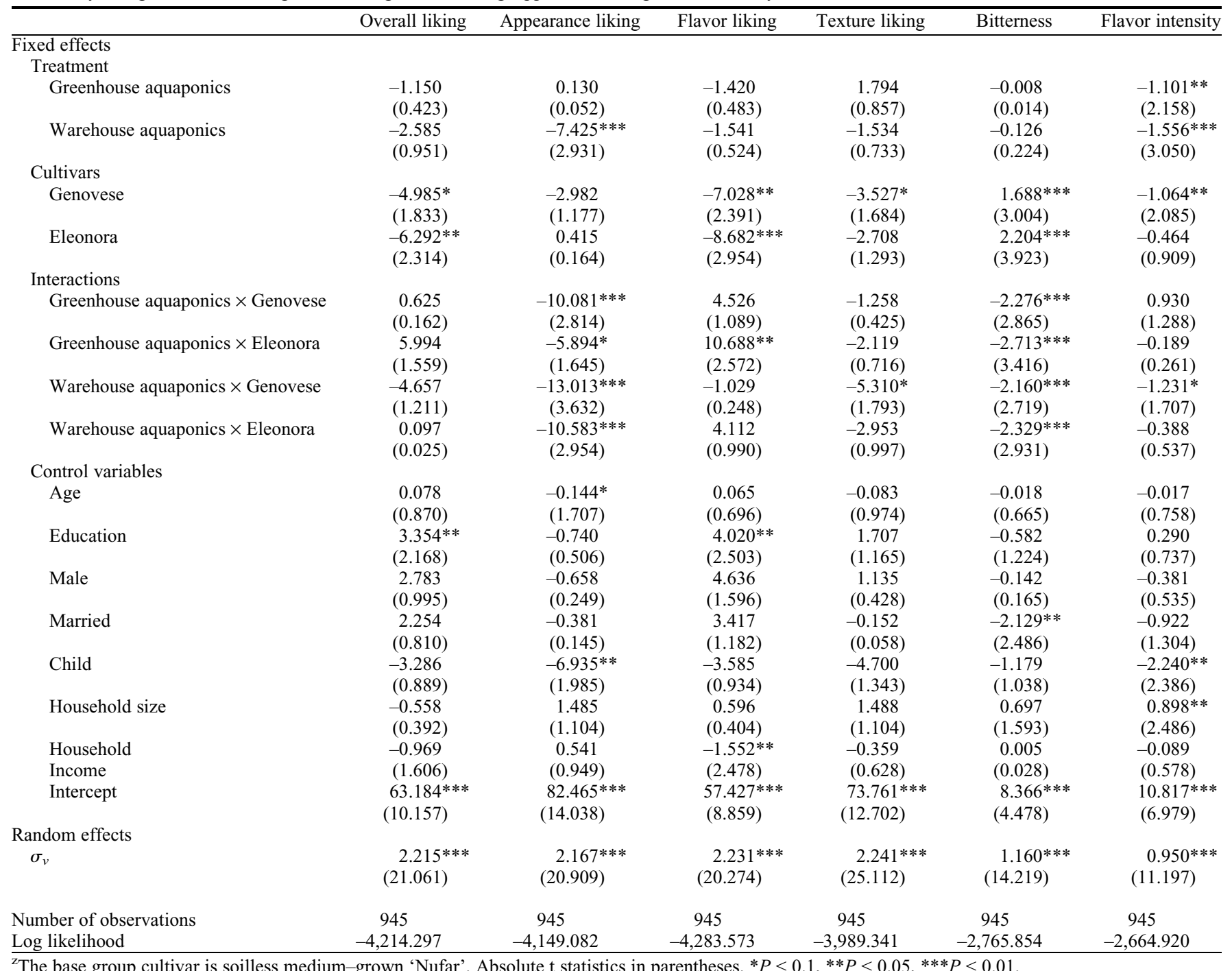

${ }^{\mathrm{z}}$ The base group cultivar is soilless medium-grown 'Nufar'. Absolute t statistics in parentheses. ${ }^{*} P<0.1, * * P<0.05, * * * P<0.01$.

conditions are shown in Table 6 and Figs. 16. Because variables of cultivars (Genovese and Eleonora) and treatments (greenhouse aquaponics and warehouse aquaponics) were all binary variables, the base group products in this specification are soilless mediumgrown Nufar cultivars. The coefficients of cultivars represent the effects of Genovese and Eleonora compared with Nufar in the soilless-grown condition. The coefficients for growing condition treatments represent the effects of different aquaponic growing methods compared with the soilless medium growing condition for 'Nufar'. The coefficients of the interaction terms represent the effects of the greenhouse or warehouse aquaponics on the ratings of different attributes for Genovese and Eleonora cultivars. For example, for the specification of appearance liking, the negative and significant coefficient for warehouse aquaponics means that warehouse aquaponics, compared with the soilless medium, decreases the average appearance ratings on 'Nufar' by 7.4. The effects of warehouse aquaponics growing condition on appearance liking of 'Genovese' can be calculated by adding the coefficients for corresponding treatment effects $(-7.4)$ and the interaction term $(-13.0)$. In other words, compared with those grown in a soilless medium, 'Genovese' grown in warehouse aquaponics received an average of 20.4 lower ratings of appearance.

The ratings on overall liking and flavor liking for 'Genovese' and 'Eleonora' were significantly lower than those for 'Nufar' in the soilless medium-grown condition. Comparing across soilless medium-grown cultivars, Eleonora and Genovese gave higher bitterness ratings compared with 'Nufar'. The likings of appearance did not differ significantly among soilless medium-grown cultivars.

The effects of aquaponics growing condition on different cultivar liking. 'Nufar' leaves grown in warehouse aquaponics had the lowest appearance ratings compared with soilless medium-grown 'Nufar'. The flavor intensity for 'Nufar' was also rated lower for aquaponically grown plants compared with soilless medium-grown plants. Regarding the overall liking, flavor liking, and flavor intensity, 'Nufar' was the best cultivar to grow in the soilless medium condition.

For 'Genovese', the aquaponics growing methods (both greenhouse and warehouse) negatively affected the liking of appearance and bitterness. Warehouse aquaponics had negative effects on flavor intensity and texture liking.

'Eleonora' grown in warehouse aquaponics had the lowest ratings of appearance liking. Aquaponics growing methods lower the ratings of appearance and bitterness on 'Eleonora'. Compared with soilless medium-grown plants, greenhouse aquaponics 'Eleonora' was rated significantly higher on flavor-liking.

In summary, warehouse aquaponics cultivars were least acceptable for all the liking attributes, whereas greenhouse aquaponically grown basil plants were not significantly disliked compared with soilless-grown plants except for appearance liking. 


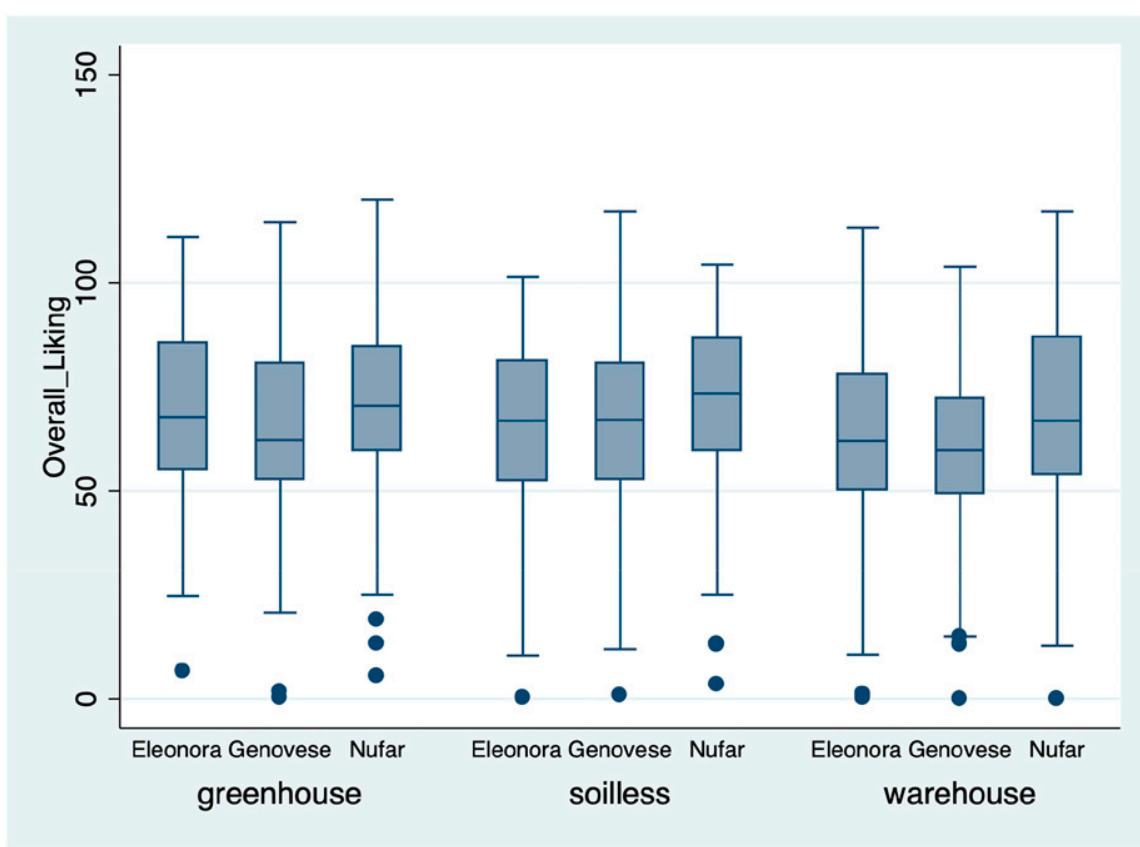

Fig. 1. Ratings of overall liking for cultivars (Eleonora, Genovese, Nufar) by growing conditions (greenhouse aquaponics, soilless medium, warehouse aquaponics) based on the 120-point labeled affective magnitude scales with the leftmost ends labeled greatest imaginable disliking and the rightmost ends labeled greatest imaginable liking.

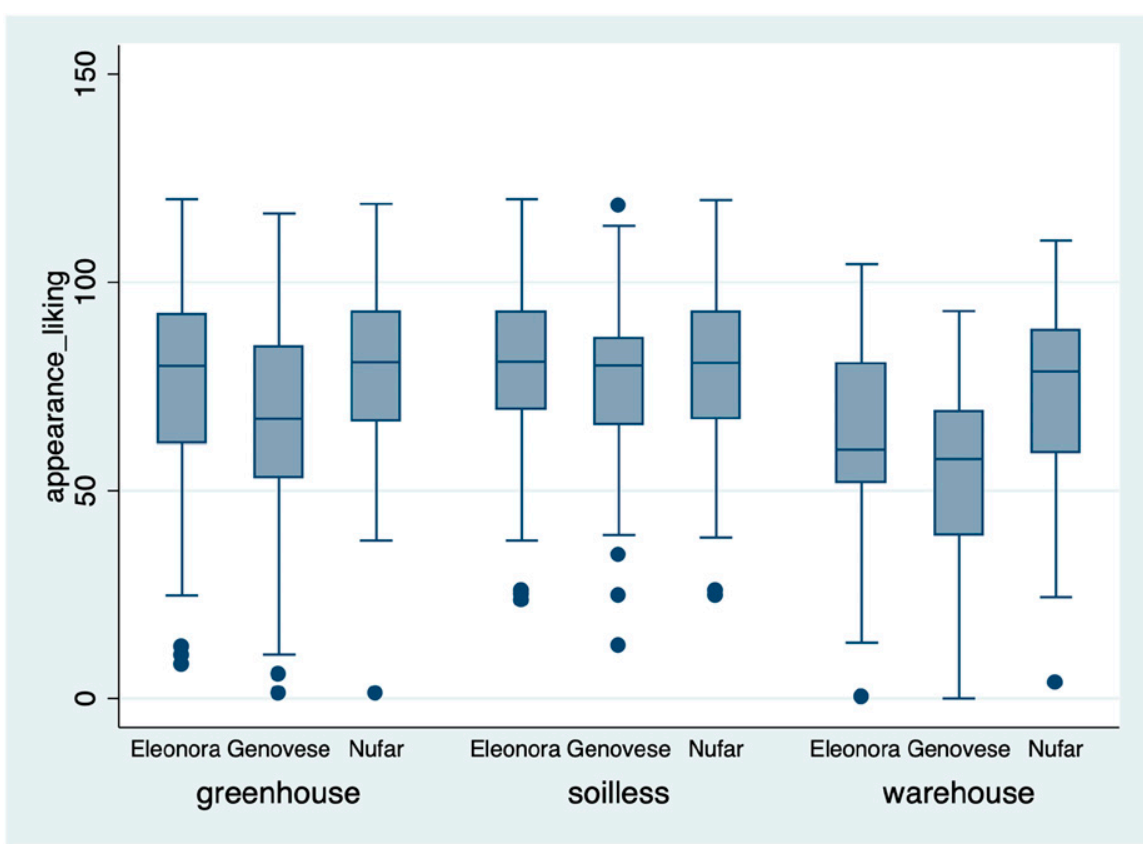

Fig. 2. Ratings of appearance liking for cultivars (Eleonora, Genovese, Nufar) by growing conditions (greenhouse aquaponics, soilless medium, warehouse aquaponics) based on 120-point labeled affective magnitude scales with the leftmost ends labeled greatest imaginable disliking and the rightmost ends labeled greatest imaginable liking.

\section{Discussion}

Participants generally liked the soilless medium-grown and greenhouse aquaponically grown basil plants more than the warehouse grown plants. However, when the interaction terms were included, and the likings of each cultivar in different growing systems were compared, no significant dif- discussed that cultivar type has a larger impact on the yield of fresh basil than production systems (Walters and Currey, 2015). With better appearances and more intense flavor than the other cultivars, Nufar was the bestliked or among the best-liked under all growing conditions. We found evidence that, when controlled for individual differences, people like the flavor of 'Eleonora' in greenhouse aquaponics better than those grown in a soilless medium. Therefore, aquaponic growers of basil should choose production systems and cultivars not only based on the yield but also consider the sensory likings of selected cultivars under different growing conditions.

Moreover, consumer perception of aquaponics affects consumer preferences of aquaponic produce. Previous studies on aquaponically grown lettuce suggested that consumers' willingness to pay for aquaponics and soilless medium-grown produce are similar (Short et al., 2018). Consumers are generally neutral or favorable to aquaponic products (Short et al., 2018; Tamin et al., 2015) and think of aquaponic products as green products that can benefit the environment and health. Although the appearance for greenhouse-grown basil cultivars was not preferred, the overall liking, flavor liking, texture liking, and flavor intensity for greenhouse aquaponics were not significantly different from soilless medium-grown cultivars, and greenhouse aquaponics even gives better flavors. In the University of the Virgin Islands commercial aquaponic system, basil has the potential to be a high-value specialty crop (Ferrarezi and Bailey, 2019). Basil growers with greenhouse aquaponics could promote their produce as green products and possibly get price premiums for the environmental-friendly label and the better flavor. A recent study (Barnhart et al., 2016) suggested that the presence of some environmental bacteria, such as Listeria spp., in aquaponic-grown crops are less, if not the same, compared with hydroponically grown crops, but consumers lack this knowledge. Therefore, more consumer education on the benefits of the aquaponic growing method for sustainable agricultural and greenhouse gas emission reduction may be essential to improve the acceptability of aquaponically grown produce. The present study focused on evaluating consumer sensory likings of aquaponically grown basil plants when the respondents have no knowledge of the production methods or cultivars, and the ratings of basil cultivars were all based on intrinsic attributes. Future studies could measure consumer acceptability ratings when the respondents would also see aquaponics or soilless medium-grown labels.

Our results have important implications for producers. Basil cultivars grown in aquaponics do not necessarily have better appearance or flavor intensity, but the selection of cultivars is more influential than the production methods. Producers should choose basil cultivars based on cultivar performance, consumer acceptability, and the adopted production systems. With better yields in the aquaponic system and appropriate marketing, producers might obtain a premium price for aquaponically grown basil plants. The 


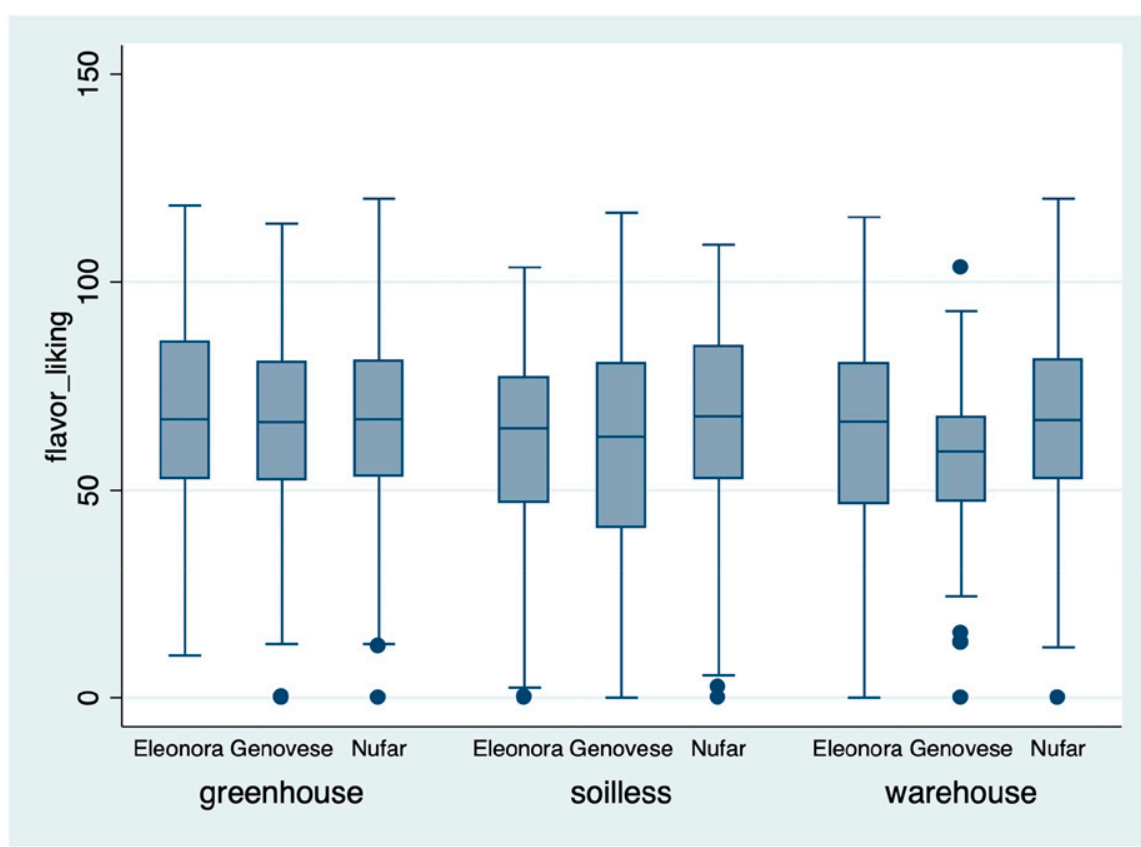

Fig. 3. Ratings of flavor liking for cultivars (Eleonora, Genovese, Nufar) by growing conditions (greenhouse aquaponics, soilless medium, warehouse aquaponics) based on 120-point labeled affective magnitude scales with the leftmost ends labeled greatest imaginable disliking and the rightmost ends labeled greatest imaginable liking.

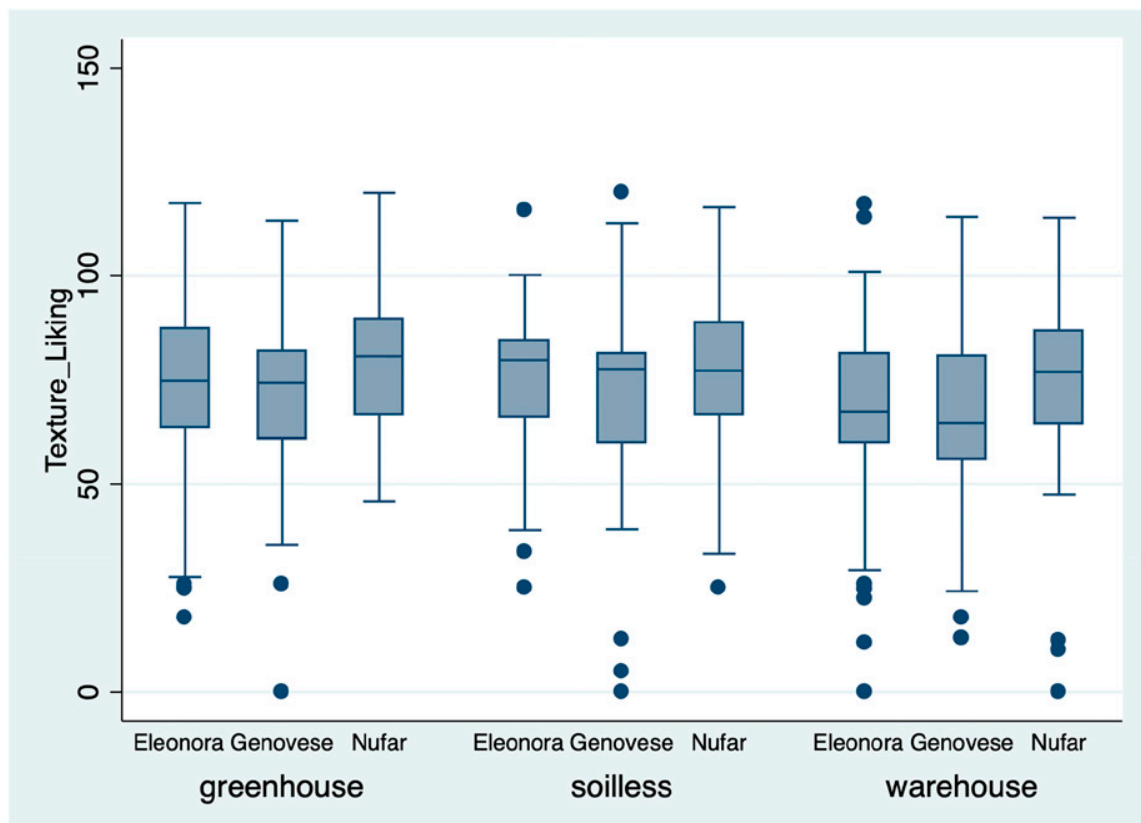

Fig. 4. Ratings of texture liking for cultivars (Eleonora, Genovese, Nufar) by growing conditions (greenhouse aquaponics, soilless medium, warehouse aquaponics) based on 120-point labeled affective magnitude scales with the leftmost ends labeled greatest imaginable disliking and the rightmost ends labeled greatest imaginable liking.

aquaponics industry should build a consumer base by promoting the green and sustainable nature of aquaponic production methods.

\section{Conclusions}

Although previous studies have focused on the production aspects and consumer per- ceptions of aquaponically grown produce, the present study provides a broader view of consumer preferences for aquaponic products by investigating the sensory performance of different cultivars under aquaponically and soilless medium-grown conditions. The sensory approach showed that the difference in likings of basil leaves results from the three variations in growing methods and basil cultivars. With individual-specific random effects controlled in a linear mixed effect model, we found that participants liked the soilless medium-grown and greenhouse aquaponically grown cultivars more than the warehouse aquaponically grown cultivars. The soilless medium-grown breed had the highest flavor intensity, followed by the greenhouse aquaponic grown and then by the warehouse aquaponic grown. Basil leaves grown in aquaponics were less preferred in appearance compared with soilless medium-grown basil, but leaves from aquaponics plants were also less bitter. Further, when comparing production methods for specific cultivars, warehouse aquaponics was least acceptable for all the liking attributes, whereas greenhouse aquaponically grown basil cultivars were not significantly disliked compared with soilless medium-grown cultivars except for appearance liking.

\section{Literature Cited}

Abbey, M., N.O. Anderson, C. Yue, G. Short, M. Schermann, N. Phelps, P. Venturelli, and Z. Vickers. 2019a. An analysis of strawberry (Fragaria $\times$ ananassa) productivity in northern latitudinal aquaponic growing conditions. J. Amer. Pomological Soc. 73(1):22-37.

Abbey, M., N.O. Anderson, C. Yue, M. Schermann, N. Phelps, P. Venturelli, and Z. Vickers. 2019b. Lettuce (Lactuca sativa) production in northern latitudinal aquaponic growing conditions. HortScience 54:1757-1761.

Barnhart, C., L. Hayes, and D. Ringle. 2016. Food safety hazards associated with smooth-textured leafy greens produced in aquaponic, hydroponic, and soil-based systems with and without roots at retail. The University of Minnesota Aquaponics, Twin-Cities, MN

Coyle, B.D. and B. Ellison. 2017. Will Consumers Find Vertically Farmed Produce 'Out of Reach'? Choices 32(1):1-8. <https://www.jstor. org/stable/90014636?seq $=1>$.

Diver, S. and L. Rinehart. 2000. AquaponicsIntegration of hydroponics with aquaculture. ATTRA-National Sustainable Agriculture Information Service. $<$ https://attra.ncat.org/attrapub/summaries/summary.php?pub=56>.

Ferrarezi, R.S. and D.S. Bailey. 2019. Basil performance evaluation in aquaponics. HortTechnology 29:85-93.

Love, D.C., J.P. Fry, X. Li, E.S. Hill, L. Genello, K. Semmens, and R.E. Thompson. 2015. Commercial aquaponics production and profitability: Findings from an international survey. Aquaculture 435:67-74.

Savidov, N. 2004. Evaluation and development of and product market capabilities in Alberta. Ids initiative fund final report. Crop Diversification Centre South, Brooks, AB.

Savvas, D. and N. Gruda. 2018. Application of soilless culture technologies in the modern greeenhouse industry - A review. Eur. J. Hort. Sci. 83(5):280-293. <https://www.pubhort.org/ ejhs/83/5/2/83_5_2.pdf $>$.

Schutz, H.G. and A.V. Cardello. 2001. A labeled affective magnitude (LAM) scale for assessing food liking/disliking. J. Sens. Stud. 16(2):117159

Short, G., C. Yue, M. Abbey, N. Anderson, N. Phelps, P. Venturelli, and Z. Vickers. 2018. Consumer preferences for aquaponic produce: 


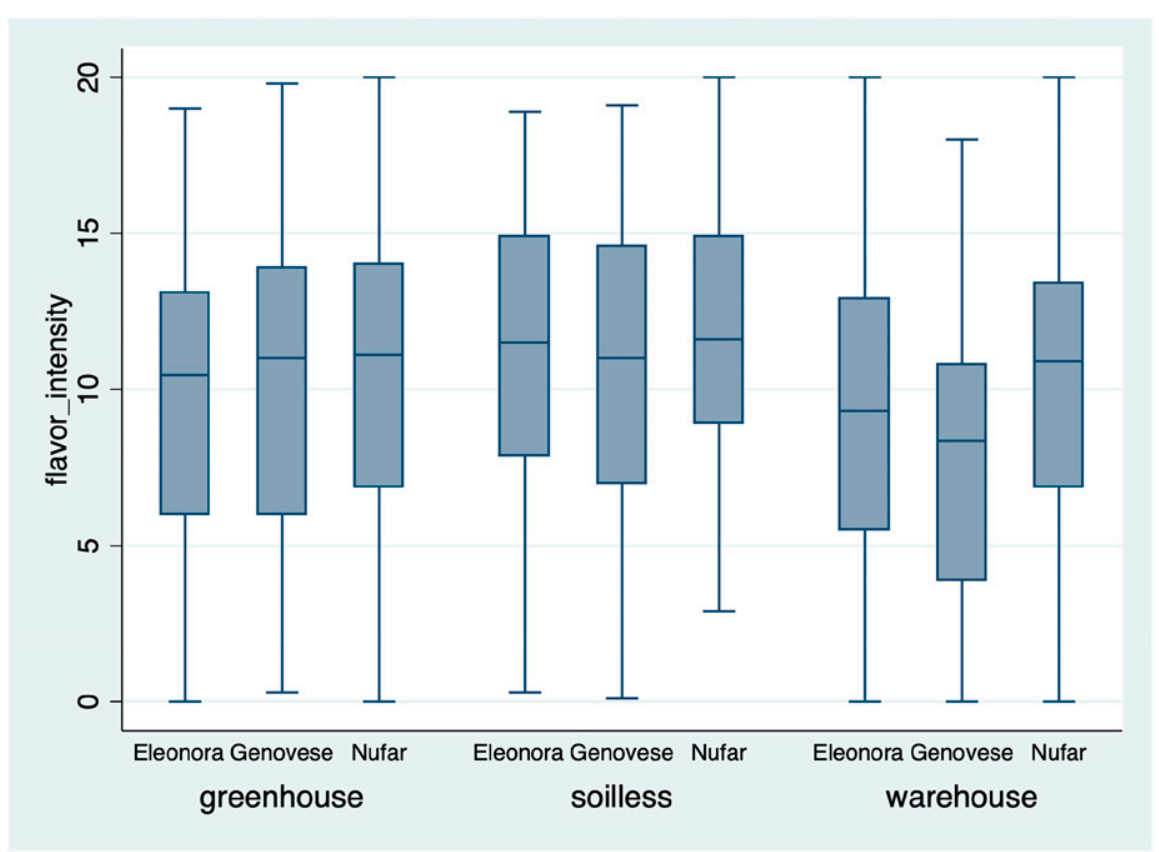

Fig. 5. Ratings of flavor intensity for cultivars (Eleonora, Genovese, Nufar) by growing conditions (greenhouse aquaponics, soilless medium, warehouse aquaponics) based on 20-point labeled affective magnitude scales with the leftmost ends labeled none and the rightmost ends labeled intense.

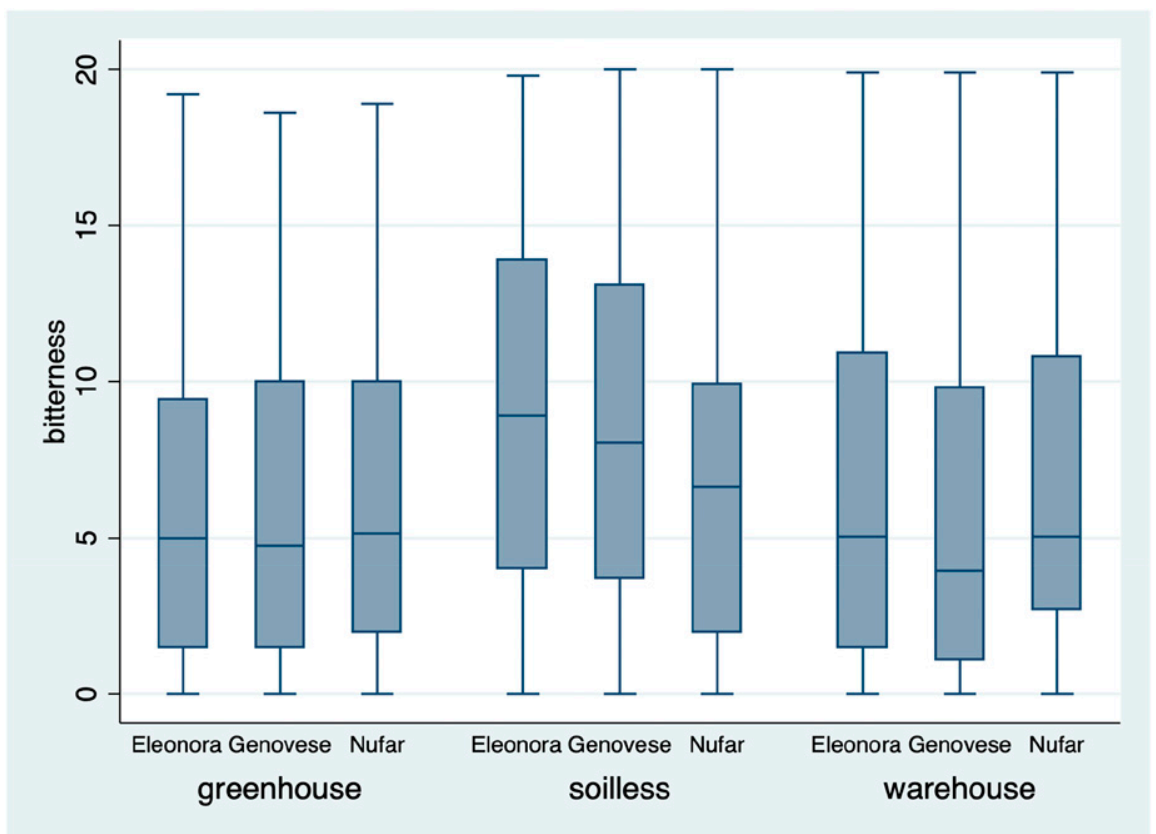

Fig. 6. Ratings on bitterness of cultivars (Eleonora, Genovese, Nufar) by growing conditions (greenhouse aquaponics, soilless medium, warehouse aquaponics) based on 20-point labeled affective magnitude scales with the leftmost ends labeled none and the rightmost ends labeled intense.
Implications from an experimental auction. Agribusiness 34(4):742-755.

Short, G., C. Yue, N. Anderson, C. Russell, and N. Phelps. 2017. Consumer perceptions of aquaponic systems. HortTechnology 27:358-366.

Singletary, K.W. 2018. Basil: A brief summary of potential health benefits. Nutr. Today 53(2):92-97. <https://journals.lww.com/ nutritiontodayonline/fulltext/2018/03000/ Basil_A_Brief_Summary_of_Potential_ Health.9.aspx>.

Somerville, C., M. Cohen, E. Pantanella, A. Stankus, and A. Lovatelli. 2014. Small-scale aquaponic food production: Integrated fish and plant farming. FAO Fisheries and Aquaculture Tech. Paper 589. <http://www.fao.org/3/ a-i4021e.pdf $>$.

Tamin, M., A. Harun, A. Estim, and S. Saufie. 2015. Consumer acceptance towards aquaponic products. IOSR J. Business Mgt. 17(8):49-64. <http:// eprints.uthm.edu.my/id/eprint/9353/1/J2168 f6b2db3430c2bdfc6cb492bd730d4f60.pdf>.

Tyson, R.V., D.D. Treadwell, and E.H. Simonne. 2011. Opportunities and challenges to sustainability in aquaponic systems. HortTechnology 21:6-13.

Walters, K.J. and C.J. Currey. 2015. Hydroponic greenhouse basil production: Comparing systems and cultivars. HortTechnology 25:645650 .

Wang, B.S., X.J. Wang, and L.K. Gong. 2009. The construction of a Williams design and randomization in cross-over clinical trials using SAS. J. Stat. Softw. 29:1-10. <https://www.researchgate.net/ profile/Bing_Shun_Wang/publication/227450909_ The_Construction_of_a_Williams_Design_and Randomization_in_Cross-Over_Clinical_Trials_ Using_SAS/links/00b7d51c0e31acd62a000000.pdf $>$.

Wilson, L. 2017. Comparing basil (Ocimum basilicum) production in hydroponic and aquaponic systems. <https://mtnchallenge.com/wp-content uploads/2016/08/Wilson-2017.pdf>. 